\title{
Deep Atmospheric Response to the Spring Kuroshio over the East China Sea*
}

\author{
HAIMING Xu AND Mimi Xu \\ Key Laboratory of Meteorological Disaster, and College of Atmospheric Sciences, Nanjing University of Information Science \\ and Technology, Nanjing, China \\ SHANG-PING XIE \\ International Pacific Research Center, and Department of Meteorology, University of Hawaii at Manoa, \\ Honolulu, Hawaii, and Physical Oceanography Laboratory, and Ocean-Atmosphere Interaction Laboratory, \\ Ocean University of China, Qingdao, China \\ YUQING WANG \\ International Pacific Research Center, and Department of Meteorology, University of Hawaii \\ at Manoa, Honolulu, Hawaii
}

(Manuscript received 28 December 2010, in final form 6 April 2011)

\begin{abstract}
The atmospheric response to the spring Kuroshio Front over the East China Sea is investigated using a suite of high-resolution satellite data and a regional atmospheric model. The atmospheric response appears to extend beyond the marine atmospheric boundary layer, with frequent occurrence of cumulus convection.

In spring, Quick Scatterometer (QuikSCAT) wind speed shows a clear effect of sea surface temperature (SST), with high (low) wind speed observed over the warm (cold) tongue. This in-phase relationship between SST and surface wind speed is indicative of SST influence on the atmosphere. Wind convergence is found on the warmer flank of the Kuroshio Front, accompanied by a narrow rainband. The analysis of satellite-borne radar measurements indicates that deep convection appears over the Kuroshio warm tongue in the spring season, with enhanced convective precipitation, frequent occurrence of cumulus convection, and increased precipitation (cloud) tops in altitude. These deep convective activities along the Kuroshio warm tongue are further supported by enhanced lightning flash rate observed by satellite and atmospheric heating estimated by a Japanese reanalysis.

The Weather Research and Forecasting (WRF) model is used to investigate the precipitation response to the spring Kuroshio SST front over the East China Sea. Forced by observed SST [control (CTL)], the model well simulates a narrow band of precipitation, high wind speed, and surface wind convergence that closely follows the Kuroshio warm current, consistent with satellite observations. This narrow rainband completely disappears in the model when the SST front is removed by horizontally smoothed SST (SmSST). The results show that it is convective precipitation that is sensitive to the Kuroshio SST front. A case study for an eastward-moving extratropical cyclone indicates that convective precipitation increases its intensity and duration in the CTL run compared to the SmSST run. Local enhancement of upward sensible and latent heat fluxes and convective instability in the lower atmosphere are the key to anchoring the narrow band of convective precipitation that closely follows the Kuroshio.
\end{abstract}

* International Pacific Research Center Publication Number 789 and School of Ocean and Earth Science and Technology Publication Number 8156

Corresponding author address: Dr. Haiming $\mathrm{Xu}$, College of Atmospheric Sciences, Nanjing University of Information Science and Technology, 219 Ning Liu Rd., Nanjing 210044, China.

E-mail: haimingx@gmail.com

\section{Introduction}

The East China Sea is one of the largest shelf seas of the world. It is surrounded by the Asian continent to the west and north and the Korean Peninsula and Ryukyu Islands to the east. Supporting heavy shipping, fishing, and oil-drilling activities, it is of great economic and climatic importance for the half billion people living in its coastal regions. The Kuroshio, a western boundary 
current of the North Pacific subtropical gyre, enters the East China Sea east of Taiwan, flows northeastward along the continental slope, and then back into the North Pacific south of the Island of Yaku-shima, Japan. This current carries warm/saline water from the tropics and is visible as a warm tongue in the sea surface temperature (SST) field between the continental shelf and Ryukyu Islands in winter and spring. A sharp SST frontthe Kuroshio Front-forms between the warm Kuroshio and the cold shelf water.

There is extensive literature on SST frontal effects on the overlying marine atmospheric boundary layer (MABL; see reviews by Chelton et al. 2004; Xie 2004; Small et al. 2008; Chelton and Xie 2010). In particular, recent highresolution satellite measurements provide new insights into the ocean-atmosphere interaction over SST fronts. For example, the Tropical Rainfall Measuring Mission (TRMM) Microwave Imager (TMI) indicates that surface wind speed increases over the Kuroshio Extension (KE) warm meanders while it decreases over detached cold eddies in spring (Nonaka and Xie 2003). This inphase relationship between SST and surface wind speed indicates an oceanic-to-atmospheric influence. Based on observations of surface winds by the Quick Scatterometer (QuikSCAT) satellite, similar covariability of SST and surface wind speed is also observed in the eastern Pacific tropical instability waves (Liu et al. 2000; Hashizume et al. 2001), the winter Kuroshio in the East China Sea (Xie et al. 2002), the Kuroshio south of Japan (Xu et al. 2010), the Gulf Stream (Chelton et al. 2004; Xie 2004), the Agulhas Return Current (O'Neill et al. 2003, 2005), and the Brazil-Malvinas Currents (Tokinaga et al. 2005). Wallace et al. (1989) proposed the following vertical mixing mechanism for such an in-phase SST-wind relationship: on the warmer flank of the front, the surface atmosphere is unstable and the intensified vertical mixing transfers large momentum from above to accelerate the surface wind. Direct atmospheric soundings and satellite observations provide some support for this vertical mixing mechanism (Hashizume et al. 2002; Tokinaga et al. 2006; O'Neill et al. 2005). However, the change in stratification is also expected to affect the momentum exchange to the surface, thereby the surface stress and surface roughness. This complicates the interpretation of the scatterometry data used in many of the above studies (Monahan 2008).

More recent studies show that atmospheric response can extend well into the free troposphere near sharp SST fronts. Minobe et al. (2008) demonstrated that surface wind convergence, enhanced evaporation and rain, deep ascent in the midtroposphere, and frequent occurrences of high cloud tops appear just over the Gulf Stream current axis. Minobe et al. (2010) also observed two types of atmospheric response to the Gulf Stream SST front with different seasonality and spatial distribution: a shallowheating mode dominating the Gulf Stream proper in winter and a deep-heating mode over the Florida Current and the western Gulf Stream proper in summer. Kuwano-Yoshida et al. (2010) investigated the precipitation response to the Gulf Stream SST front using an atmospheric general circulation model and showed that it is convective precipitation that is sensitive to the SST fronts. Similarly, Tokinaga et al. (2009) reported tropospheric response to the Kuroshio Extension east of Japan, characterized by enhanced precipitation, frequent cloud occurrence, and enhanced lightning activities. These studies show that climatic influences of ocean currents and accompanied SST fronts extend much higher in the atmosphere than previously thought.

The Kuroshio leaves a visible warm tongue and an associated sharp SST front over the East China Sea, especially in winter and spring although the front is somewhat weaker than the Gulf Stream. Using high-resolution satellite measurements, Xie et al. (2002) reported that high winds, wind convergences, and increased cloudiness are found over the warm tongue on the warmer flank of the Kuroshio Front in the winter season, indicative of an oceanic-to-atmospheric influence. The question remains as to whether deep atmospheric responses like those along the Gulf Stream also exist over the East China Sea. The present study investigates SST frontal effects on precipitation over the East China Sea in spring. Using a suite of satellite measurements and a state-of-the-art atmospheric model, we find that the Kuroshio Front and accompanied warm tongue do induce deep convection activities over the East China Sea in spring.

The rest of the paper is organized as follows. Section 2 introduces the datasets used in the study. Section 3 presents the precipitation response to the Kuroshio SST front based on observations. Section 4 describes an atmospheric model and presents its simulations, and section 5 is a summary.

\section{Data}

In this study, we use two sets of TRMM satellite's Precipitation Radar (PR) datasets: the level 2 PR product 2A25 (Iguchi et al. 2000) and level 2 PR product 2A23 (Awaka et al. 1997), both are version 6. The level 2 PR product $2 \mathrm{~A} 25$ provides the gridded, three-dimensional (3D), and attenuation-corrected reflectivity factor and rainfall rate while the level 2 PR product $2 \mathrm{~A} 23$ provides the categorization of the echo and precipitation as convective, stratiform, or other. The latter is a twodimensional product and does not have a vertical dimension. The PR 2A23 rain classifications are based on 
the combination of a vertical profile method (the $\mathrm{V}$ method) and a horizontal profile method (the $\mathrm{H}$ method) described by Awaka et al. (1997, 2007). The V and H methods are first applied separately; then their unified result is used to classify the raining pixel into one of the three categories. The use of these two methods ensures that the rainfall amount derived from the other-type rain pixels is very small. A detailed description of this rain-type classification procedure can be found in the TRMM Science Data and Information System file specification under dataset 2A23 (see NASA Goddard Space Flight Center 2011). We use the TRMM PR product $2 \mathrm{~A} 23$ to separate radar precipitation into convective and stratiform components. The 3D TRMM PR $2 \mathrm{~A} 25$ precipitation rate data are interpolated, using the technique described in Houze et al. (2007), from an irregular to a 3D geographic grid of $0.1^{\circ} \times 0.1^{\circ}$ resolution in the horizontal and $0.25-\mathrm{km}$ resolution in the vertical. To date, the TRMM PR datasets have been widely used and led to a greater understanding of precipitation processes and variability (e.g., Houze et al. 2007; Yang and Smith 2008; Romatschke et al. 2010).

For surface precipitation, we use the TRMM 3B43 product, derived from TRMM and other satellite observations: geosynchronous infrared radiometer, Special Sensor Microwave Imager (SSM/I), rain gauge, and the TRMM 3B31 product based on the TRMM PR and microwave imager on a monthly $0.25^{\circ} \times 0.25^{\circ}$ grid between $50^{\circ} \mathrm{S}$ and $50^{\circ} \mathrm{N}$. The TRMM products are available at the Goddard Earth Sciences Data and Information Services Center.

The microwave scatterometer SeaWinds on the National Aeronautics and Space Administration (NASA) QuikSCAT satellite measures surface roughness that is converted to the equivalent neutral wind velocity over the global ocean. It has revealed rich wind structures on the shorter spatial scales around the world (Chelton et al. 2004; Xie 2004; Sampe and Xie 2007). We use the monthly wind velocity product available at Remote Sensing Systems $(\mathrm{RSS})$ on a $0.25^{\circ} \times 0.25^{\circ}$ grid.

As an indicator of atmospheric convective activity, we use the monthly climatology of lightning activity observed by the Optical Transient Detector (OTD) onboard the Micro Laboratory-1 satellite from April 1995 to March 2000 and Lightning Imaging Sensor (LIS) onboard the TRMM satellite from January 1998 to December 2005. Christian et al. (2003) have reported that lightning is predominant in the North Atlantic and western North Pacific year-round as cold air blows over the warm ocean surface. The LIS/OTD merged monthly climatology is available at the NASA Global Hydrology Resource Center on a $0.5^{\circ} \times 0.5^{\circ}$ grid.

Two SST analyses are produced daily on a $0.25^{\circ} \times 0.25^{\circ}$ grid at NOAA's National Climate Data Center (NCDC) as described in Reynolds et al. (2007) and Reynold and Chelton (2010). One analysis uses in situ and Advanced Very High Resolution Radiometer (AVHRR) data (i.e., AVHRR-only). The second analysis adds Advanced Microwave Scanning Radiometer (AMSR) data when AMSR becomes available in June 2002 (i.e., AVHRR + AMSR). Here, we use the first SST dataset, which is available since January 1981.

We also use the monthly fields of vertical integrated diabatic heating rate and three-dimensional atmospheric heating rate from the Japanese 25-yr Reanalysis Project (JRA-25; Onogi et al. 2007) produced jointly by the Japan Meteorological Agency (JMA) and the Central Research Institute of Electric Power Industry. These fields are available on a $1.25^{\circ} \times 1.25^{\circ}$ grid and 40 vertical levels from 1979 to 2004. The product is updated for the subsequent period using the same data assimilation system called the JMA Climate Data Assimilation System (JCDAS).

Monthly climatologies are constructed for TRMM precipitation rate, QuikSCAT surface wind velocity, NCDC SST, and JRA-25 atmospheric heating rate for a common period from January 2000 to December 2008.

\section{Observational analysis}

\section{a. Surface wind and precipitation}

As in winter, the Kuroshio leaves a warm tongue in the SST field between the continental shelf and Ryukyu Islands (around $26.3^{\circ} \mathrm{N}, 127.7^{\circ} \mathrm{E}$ ) in the spring season (Fig. 1). Off the Chinese coast, a northward-directing warm tongue exists and can be traced up to $31^{\circ} \mathrm{N}$. A more pronounced warm tongue exists to the northeast, facing westward west of Cheju Island $\left(33.5^{\circ} \mathrm{N}, 126.6^{\circ} \mathrm{E}\right)$, Korea, and then pointing north in the Yellow Sea. Between these southwest and northeast warm tongues is a southeastward cold tongue. As a result, a sharp SST front-the Kuroshio Front-forms between the warm Kuroshio and the cold shelf water. Xie et al. (2002) proposed that similar SST structures exist in winter and are mainly controlled by the submerged ocean bottom topography through intense vertical mixing. This vertical mixing mechanism may also work in spring.

On seasonal average, the spring surface winds are northerly to northeasterly over the Yellow and East China Seas (Fig. 1b). The QuikSCAT wind speed shows a clear association with SST, with high (low) wind speed observed over the warm (cold) tongue. In particular, the local wind speed maximum (minimum) along the northeast warm (cold) tongue is unlikely to be due to the orographic effect over land because it is sufficiently far from the coast. To the south along the warmer flank of the 


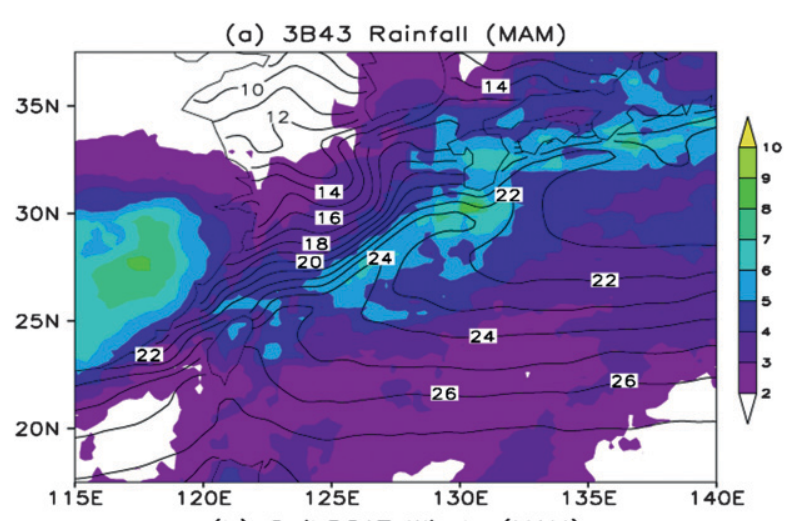

(b) QuikSCAT Winds (MAM)

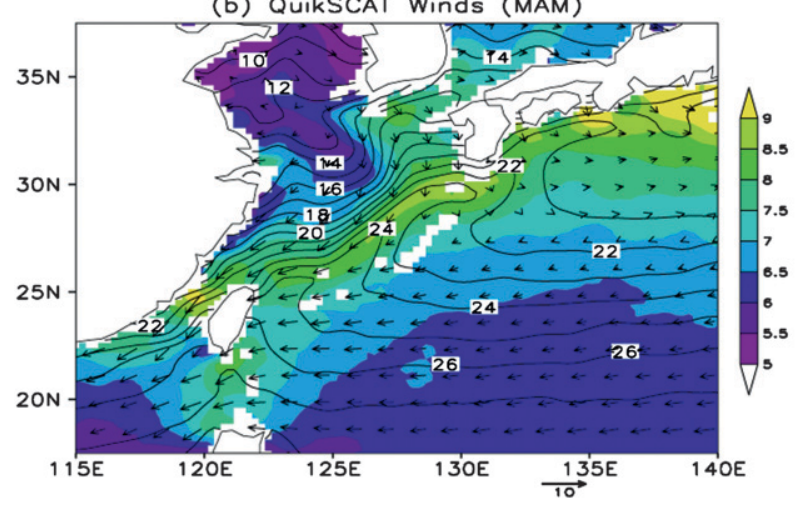

(c) QuikSCAT Wind Div. (MAM)

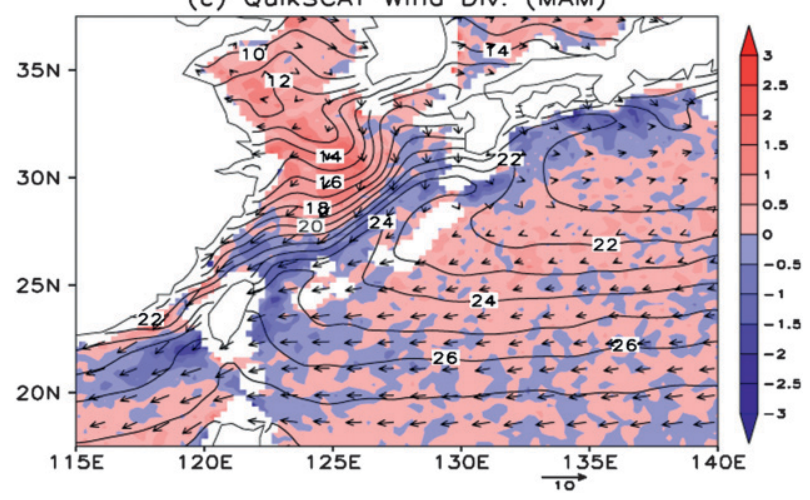

FIG. 1. MAM climatology of (a) 3B43 precipitation (shade in mm day ${ }^{-1}$ ), (b) QuikSCAT wind speed (shade in $\mathrm{m} \mathrm{s}^{-1}$ ) and wind velocities (vectors), and (c) their divergence (shade in $10^{-5} \mathrm{~s}^{-1}$ ). Climatology of MAM AVHRR SST (contours at intervals of $1.0^{\circ} \mathrm{C}$ ) is plotted.

Kuroshio Front, a wind speed maximum is located $100-200 \mathrm{~km}$ from the rather flat island of Okinawa, again a likely effect of SST rather than orography. This in-phase relationship between SST and surface wind speed is indicative of SST influencing the atmosphere (Xie 2004). There are three mechanisms on SST variations affecting the atmosphere. First, on the warmer flank of an SST front, a decrease of atmospheric stability intensifies vertical mixing and brings fast-moving air from aloft to accelerate the surface wind (Wallace et al.
1989; Xie et al. 1998). Second, the SST increase warms the atmospheric boundary layer by sensible and latent heat and lowers sea level pressure (SLP). The resultant SLP gradient causes wind adjustment (Lindzen and Nigam 1987; Small et al. 2003). Third, the enhanced mixing leads to enhanced surface stress, which could be responsible for some of the in-phase relationship between SST and the neutral wind speed estimated by QuikSCAT. However, while the actual value of nearsurface wind may differ from QuikSCAT, the actual divergence/convergence patterns are expected to be similar. This is investigated further in section 4 .

Figure $1 \mathrm{c}$ presents the seasonal mean convergence of equivalent neutral wind velocity at $10 \mathrm{~m}$, estimated from QiukSCAT observations. Wind convergence (divergence) is found on the warmer (colder) flank of the Kuroshio Front. In particular, the wind convergence follows the main warm tongue that meanders from the southern tip of Kyushu Island all the way to the southeast coast of Japan. Upon closer inspection, wind convergence (divergence) tends to take place where the wind blows down- (up-) SST gradient over the Yellow and East China Seas, a phase relation consistent with vertical mixing argument.

Over the warmer part of the East China Sea, precipitation is markedly modulated by SST (Fig. 1a). In particular, large precipitation is observed on the warmer flank of the Kuroshio Front, with enhanced precipitation just around the warm tongue of the Kuroshio. Conversely, a reduction in precipitation is found over the cold tongue. The enhanced precipitation over the main warm tongue and the Kuroshio is highly correlated with the surface wind convergence, which is mainly controlled by the SST gradient (Fig. 1c).

\section{b. Convective and stratiform precipitation}

Figure 2 presents the spring [March-May (MAM)] climatologies of TRMM 2A25 surface convective and stratiform precipitation rates for 2000-08. Like the Gulf Stream (Minobe et al. 2010), the warm Kuroshio over the East China Sea anchors a distinctive convective rainband, although SSTs along the warm tongue are far below $26^{\circ}-27^{\circ} \mathrm{C}-\mathrm{a}$ SST threshold for deep convection in the tropics, depending upon region and season (Graham and Barnett 1987; Sud et al. 1999). The convective rainband is mostly pronounced in the spring season, with enhanced convective precipitation around the axis of the Kuroshio (Fig. 2a). Convective precipitation rates in autumn also show a convective rainband but with weaker magnitude (not shown). The close collocation among the convective rainband, Kuroshio warm current, and its associated Kuroshio Front indicates that the convective activities are not only related to the magnitude of 

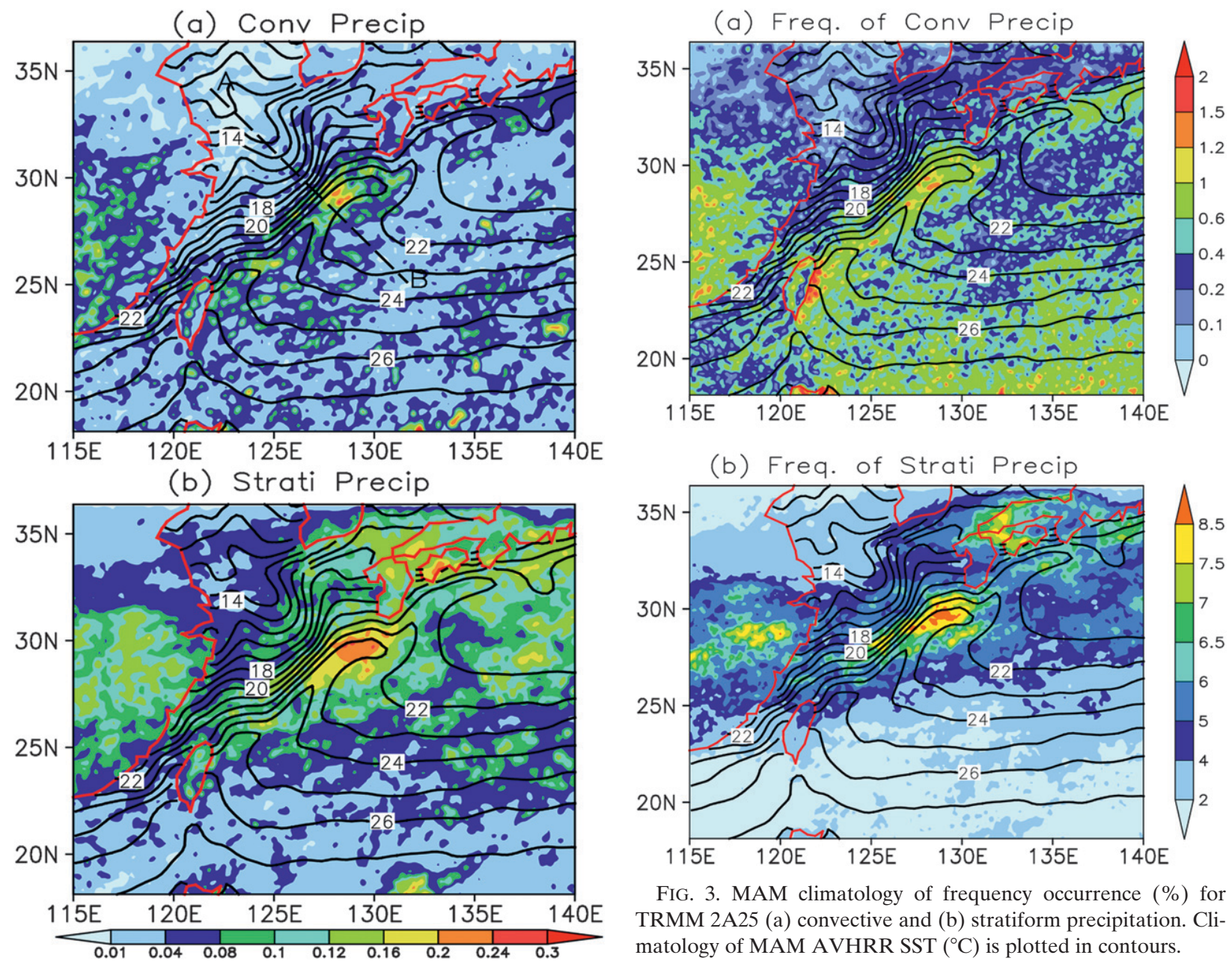

FIG. 3. MAM climatology of frequency occurrence (\%) for TRMM 2A25 (a) convective and (b) stratiform precipitation. Climatology of MAM AVHRR SST $\left({ }^{\circ} \mathrm{C}\right)$ is plotted in contours.

FIG. 2. MAM climatology of TRMM 2A25 surface (a) convective and (b) stratiform precipitation rates (shade in $\mathrm{mm} \mathrm{h}^{-1}$ ). Climatology of MAM NCDC AVHRR SST $\left({ }^{\circ} \mathrm{C}\right)$ is plotted in contours.

SST, but they are also related to SST gradients, which induce wind convergence on the warmer flank of the Kuroshio Front.

In contrast to the narrow convective rainband, stratiform precipitation exists extensively over the western North Pacific. The stratiform precipitation also reaches its maximum along the main warm tongue of the Kuroshio, forming a stratiform rainband. However, large stratiform precipitation appears over both sides of the Kuroshio and the Kuroshio Extension off the east coast of Japan where the SSTs are relatively low. Previous studies have shown an interaction between SST and low cloudiness over the western North Pacific, characterized by negative correlation: a SST decrease increases low cloudiness owing to strengthened atmospheric stratification, reducing solar radiation at the sea surface and amplifying the initial cooling (Klein and Hartmann 1993; Norris et al.

1998). Additionally, atmospheric thermal advection also plays an important role in determining the cloud type over the western North Pacific (Norris 1998a,b; Norris and Iacobellis 2005). Northerly-induced cold advection over the SST gradient tends to produce cumulus and stratocumulus clouds by developing an inversioncapped MABL while southerly-induced warm/moist advection over the northward-decreasing SST, on the other hand, increases the stratification of the surface layer, forming sea fog.

The relationship between convective/stratiform precipitation and the main warm Kuroshio can be better seen in the frequency occurrences of the convective and stratiform rainfall (Fig. 3). Clearly, the warm Kuroshio anchors a high-frequency occurrence band of convective precipitation, which follows the Kuroshio warm tongue from the warm waters east of Taiwan to the northeastern East China Sea. The high-frequency band of stratiform precipitation, however, is confined to the northern part of the Kuroshio over the northeastern East China Sea. It generally shifts to the cold side of the warm Kuroshio as 


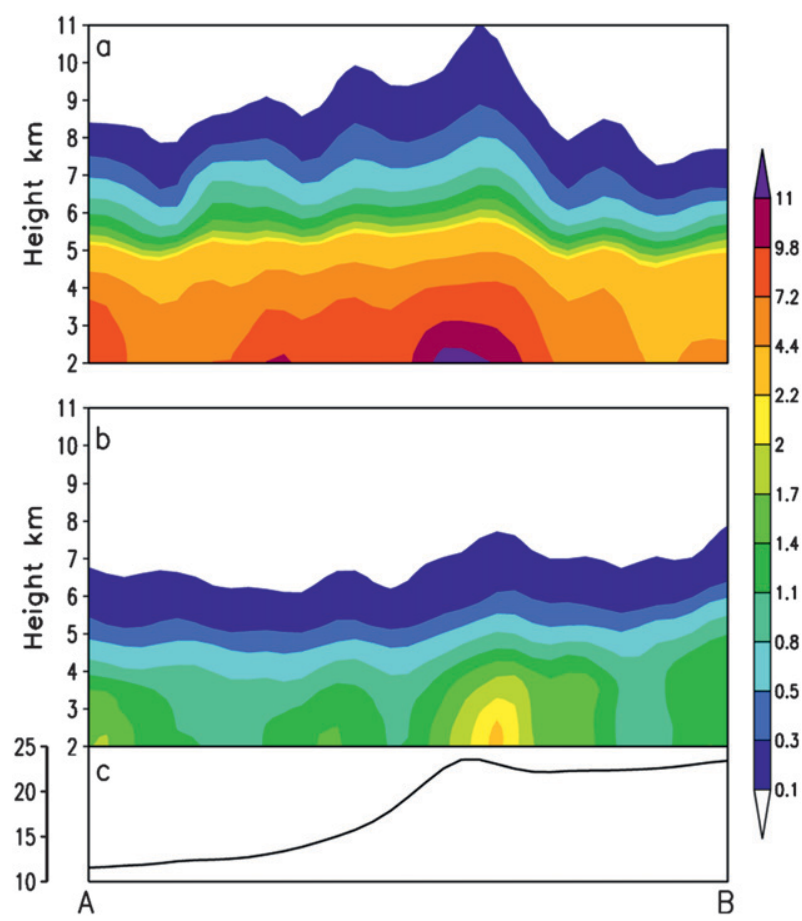

FIG. 4. Vertical cross sections of TRMM 2A25 conditional (a) convective and (b) stratiform precipitation rates (shade in $\mathrm{mm} \mathrm{h}^{-1}$ ) along line AB in Fig. 2a. (c) AVHRR SST variation $\left({ }^{\circ} \mathrm{C}\right)$ along line $\mathrm{AB}$ is shown.

it extends southward. It is noteworthy that the frequency of stratiform precipitation occurrence is much higher than ( $\sim 8$ times as large as) that of convective precipitation (note different color bar in Figs. 3a,b). Additionally, the highest convective rainfall frequency over the warm waters east of Taiwan Island is probably related to orographic effect of the narrow Central Mountain Range along the east coast of Taiwan Island. Xie et al. (2006) found that narrow mountain ranges are an important organizing agent anchoring the Asian summer monsoon convection centers on the windward side. Similarly, as the northeasterly wind impinges on the narrow north-south-oriented Central Mountain Range, moistureladen air is forced to rise, causing intense convection on the windward side.

Figure 4 presents vertical cross sections of conditional convective/stratiform precipitation rates along the line $\mathrm{AB}$ as shown in Fig. 2a. The conditional precipitation rate is the precipitation rate conditioned on rain and rain type (Hirose and Nakamura 2002). As shown before, the observed frequency of convective precipitation occurrence is much less than that of stratiform precipitation occurrence, however, convective precipitation rate is much larger than the stratiform precipitation rate. Both convective and stratiform precipitation rates reach their maximum just above the warm SST peak around $\left(28.9^{\circ} \mathrm{N}\right.$,

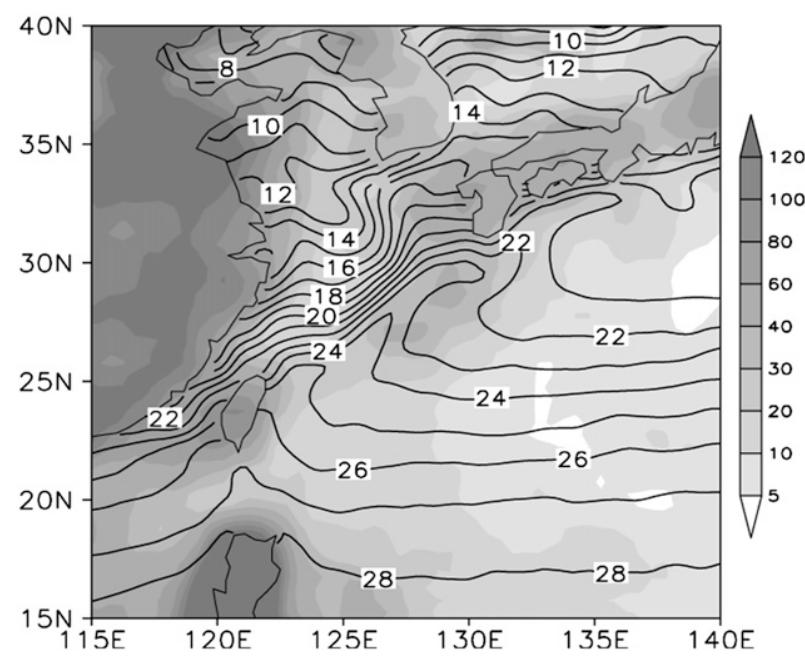

FIG. 5. MAM climatology of lightning activity observed by LIS/ OTD (shade in $100 \mathrm{~km}^{-2}$ month $^{-1}$ ). Superimposed are the MAM NCDC AVHRR SSTs (contours at intervals of $1.0^{\circ} \mathrm{C}$ ).

$\left.127.6^{\circ} \mathrm{E}\right)$ while decreasing on its both sides. Note that stratiform precipitation mainly occurs in the midlower troposphere below $7 \mathrm{~km}$ in the vertical while convective precipitation reaches much higher altitudes. In particular, the convective precipitation top reaches as high as $10 \mathrm{~km}$ above the warm Kuroshio (Fig. 4b). Lightning observations by the LIS/OTD support springtime convection over the Kuroshio (Fig. 5). Notably, springtime lightning flash rate displays a local maximum along the Kuroshio, closely collocated with enhanced convective precipitation and its frequency occurrence. These results indicate that deep convection frequently occurs there in spring.

\section{c. Atmospheric heating}

Results in the previous subsections show that deep convection occurs along the main Kuroshio in the spring season. It is interesting, therefore, to examine atmospheric heating features. JRA-25/JCDAS provides the three-dimensional atmospheric heating rate in the following five components: advection, convective heating, large-scale condensation, vertical diffusion, and solar and longwave radiative heating rates. For simplicity, the sum of convective and large-scale condensational heating rates is referred to as latent heating. The vertical diffusion includes the sensible heat flux from the surface and is referred to as sensible heating. We focus on the latent and sensible heating rates, as they are much larger than the net radiative heating rates.

Figure 6a presents the spring climatologies of JRA-25/ JCDAS column-integrated diabatic heating for 2000-08. Consistently, the total column diabatic heating displays a distinctive heating band along the Kuroshio over the 
(a) Column diabatic heating (MAM)

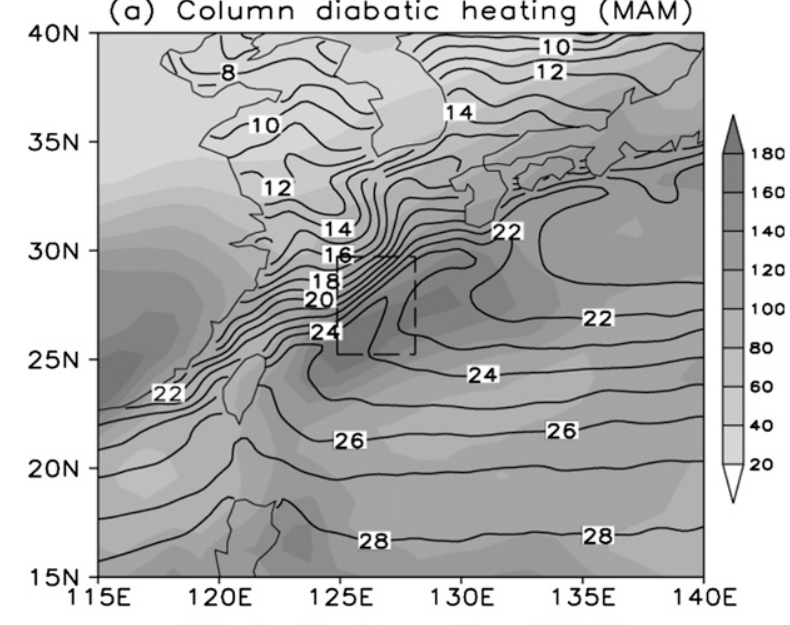

(b) Vertical profiles (MAM)

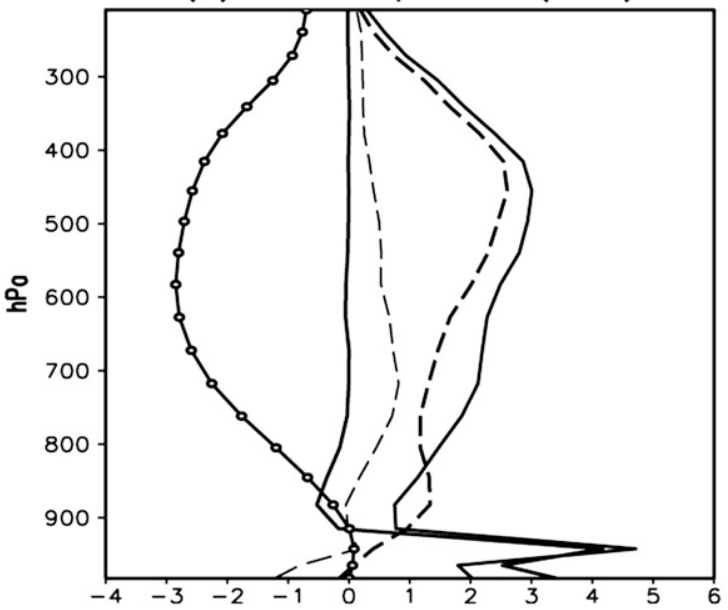

FIG. 6. (a) JRA-25 MAM climatology of column-integrated diabatic heating (shade in $\mathrm{W} \mathrm{m}^{-2}$ ) and NCDC AVHRR SSTs (contours at intervals of $1.0^{\circ} \mathrm{C}$ ); (b) vertical profiles of MAM total diabatic heating rate (thick solid line in $\mathrm{K} \mathrm{day}^{-1}$ ), convective heating rate (thick dashed line in $\mathrm{K}_{\text {day }}{ }^{-1}$ ), large-scale condensational heating rate (thin dashed line in $\mathrm{K} \mathrm{day}^{-1}$ ), and sensible heating rate (thin solid line in $\mathrm{K}$ day $^{-1}$ ), and vertical $p$ velocity (line with open circle in $10^{-2} \mathrm{~Pa} \mathrm{~s}^{-1}$ ), averaged in the rectangle in (a).

East China Sea with its maximum of $200 \mathrm{~W} \mathrm{~m}^{-2}$. This high heating band slightly shifts to the east of the main Kuroshio warm tongue probably because of the coarse resolution of JRA-25 dataset on a $1.25^{\circ} \times 1.25^{\circ}$ grid. Vertical profiles of the diabatic heating rate over the Kuroshio (rectangle in Fig. 6a) show that sensible heating is observed below $900 \mathrm{hPa}$ in spring, while latent heating, mainly due to convection, occurs above $900 \mathrm{hPa}$ and gradually increases in magnitude above $800 \mathrm{hPa}$ (Fig. 6b) and reaches its maximum around $500 \mathrm{hPa}$. The convective heating displays a minor peak between $800-900 \mathrm{hPa}$ and a second major peak in the midtroposphere (400-500 hPa). The spring upward motion over the main Kuroshio also exhibit deep vertical penetration and is highly visible in the whole troposphere (Fig. 6b). The upward motion increases in magnitude above $900 \mathrm{hPa}$ and reaches its maximum in the middle troposphere (around 500$600 \mathrm{hPa}$ ). These middle-tropospheric maxima of convective heating and upward motion in this region are consistent with the aforementioned observed strong convective precipitation and enhanced lightning activities (Fig. 5).

\section{Modeling \\ a. Model and experimental design}

We use the Weather Research and Forecasting (WRF) model (version 3.1.1, Skamarock et al. 2008) to examine the spring Kuroshio's effect on the overlying atmosphere over the East China Sea. The model domain is $20^{\circ}-40^{\circ} \mathrm{N}$, $114^{\circ}-140^{\circ} \mathrm{E}$. The model uses a horizontal resolution of $15 \mathrm{~km}$ and has 50 sigma levels in the vertical. We choose the following parameterizations: the Purdue Lin microphysical parameterization (Chen and Sun 2002), the Rapid Radiative Transfer Model (Mlawer et al. 1997) and Dudhia (Dudhia 1989) schemes for longwave and shortwave radiation calculation, the Yonsei University (YSU) planetary boundary layer scheme (Hong et al. 2006), Noah land surface scheme (Chen and Dudhia 2001), and the Kain-Fritsch scheme for cumulus parameterization (Kain 2004; Kain and Fritsch 1990, 1993). The Monin-Obukhov similarity theory as the surface layer scheme is used to calculate friction velocities, exchange coefficients, and sea surface fluxes. A convective velocity following Beljaars (1994) is used to enhance surface fluxes of heat and moisture. Surface exchange coefficients for heat, moisture, and momentum are estimated using stability functions from Paulson (1970), Dyer and Hicks (1970), and Webb (1970).

The initial and lateral boundary conditions are obtained from the National Centers for Environmental Prediction (NCEP) Operational Global Final Analyses (FNL) dataset, available on a $1^{\circ}$ by $1^{\circ}$ grid with 26 vertical pressure levels from 1000 to $10 \mathrm{hPa}$. They are interpolated onto the model grids by cubic spline interpolation in the horizontal and linear interpolation in both the vertical and time based on 4 times daily analysis. For the sake of comparisons, the WRF model does not assimilate any QuikSCAT winds. Over the ocean, the NCDC AHVHRR + AMSR optimally interpolated daily SSTs on a $0.25^{\circ}$ by $0.25^{\circ}$ grid are used as the lowerboundary condition.

To examine the effect of the Kuroshio on the overlying atmosphere, we perform two experiments, one with observed SST featuring a warm tongue and an associated 


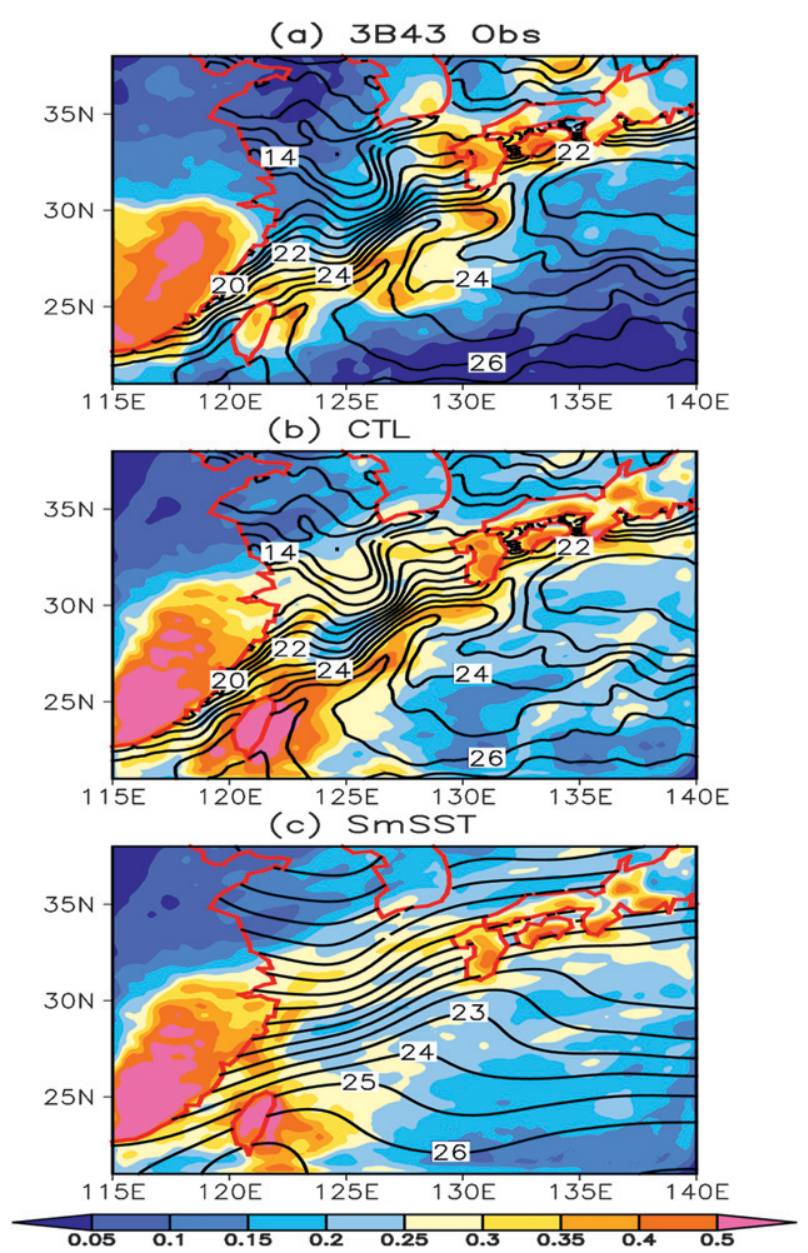

FIG. 7. Mean precipitation (color in $\mathrm{mm} \mathrm{h}^{-1}$ ) for (a) 3B43 observations, (b) model CTL, and (c) SmSST runs, averaged for April and May 2006. The 2-month (April-May 2006) mean SSTs (contours at $1.0^{\circ} \mathrm{C}$ intervals) for (a) NCDC AVHRR observations, (b) CTL, and (c) SmSST runs.

Kuroshio SST front over the East China Sea (Fig. 7b), and one with the SST field heavily smoothed such that the SST warm tongue and the associated Kuroshio Front are removed (Fig. 7c). We apply a two-dimensional, 9-point averaging for 200 times to smooth the SST field across the SST warm tongue. Here, we refer the first experiment as "control (CTL) run" and the second one as "smoothed SST (SmSST) run", respectively. The two-month mean SSTs in the CTL run exceed the SST threshold $\left(26^{\circ}-27^{\circ} \mathrm{C}\right)$ of convective precipitation over the southwest East China Sea northeast of Taiwan, however, the SSTs are below the threshold over the main warm tongue, especially over the analysis region of line $\mathrm{AB}$ as shown in Fig. 2a. Each run is initialized at 0000 UTC on 26 March 2006 and integrated through the end of May 2006. We discuss the April-May two-month means, based on 3-hourly model outputs.

\section{b. Precipitation}

Figure 7 presents the two-month (April-May 2006) mean precipitation for 3B43 observation, model CTL, and SmSST runs. In April-May, major precipitation over the western North Pacific occurs in a southwestnortheast-oriented band over the Kuroshio warm tongue in the East China Sea, a feature that the model reproduces reasonably well. However, the simulated rainband is stronger and wider than the observed one, especially over the Taiwan Island and its surrounding areas. The model also overestimates precipitation over Southeast China.

With the Kuroshio warm tongue and accompanied front over the East China Sea removed in SmSST run, the precipitation band along the Kuroshio warm tongue completely disappears (Fig. 7c). The effect of the Kuroshio on the overlying precipitation can be better seen in the difference field between the CTL and SmSST runs (Fig. 8a). A nearly southwest-northeast-oriented band of positive rainfall anomalies is just sitting on the Kuroshio, indicating that the Kuroshio acts to initiate precipitation there.

As discussed earlier, the TRMM 2A25 product distinguishes convective and stratiform precipitation from the vertical structure of precipitation radar echo (Iguchi et al. 2000). Precipitation in the WRF model can also be classified as being either convective (generated from the subgrid-scale cumulus parameterization scheme) or stratiform (from the resolved grid-scale microphysical scheme). The former follows the Kain-Fritsch cumulus parameterization (Kain 2004), utilizing a simple cloud model with moist updrafts and downdrafts, including the effects of detrainment, entrainment, and relatively simple microphysics; and the latter considers six classes of hydrometeors (water vapor, cloud water, cloud ice, snow and graupel). Although these classifications are not strictly equivalent, convective precipitation from the WRF cumulus parameterization scheme can be considered as resulting from convectively unstable situations. Figure $8 \mathrm{~b}$ shows the simulated convective precipitation difference between the CTL and SmSST runs. Comparison of Fig. 8a and Fig. 8b clearly shows that the convective precipitation difference pattern is almost the same as the total precipitation difference pattern, indicating that it is cumulus convection not stratiform precipitation that is sensitive to the Kuroshio SST front and predominantly contributes to the narrow precipitation band formation in the CTL run. Our result presented here is consistent with the result of KuwanoYoshida et al. (2010), who investigated the precipitation response to the Gulf Stream using an atmospheric general circulation model and found that it is convective precipitation that is sensitive to SST gradients. 

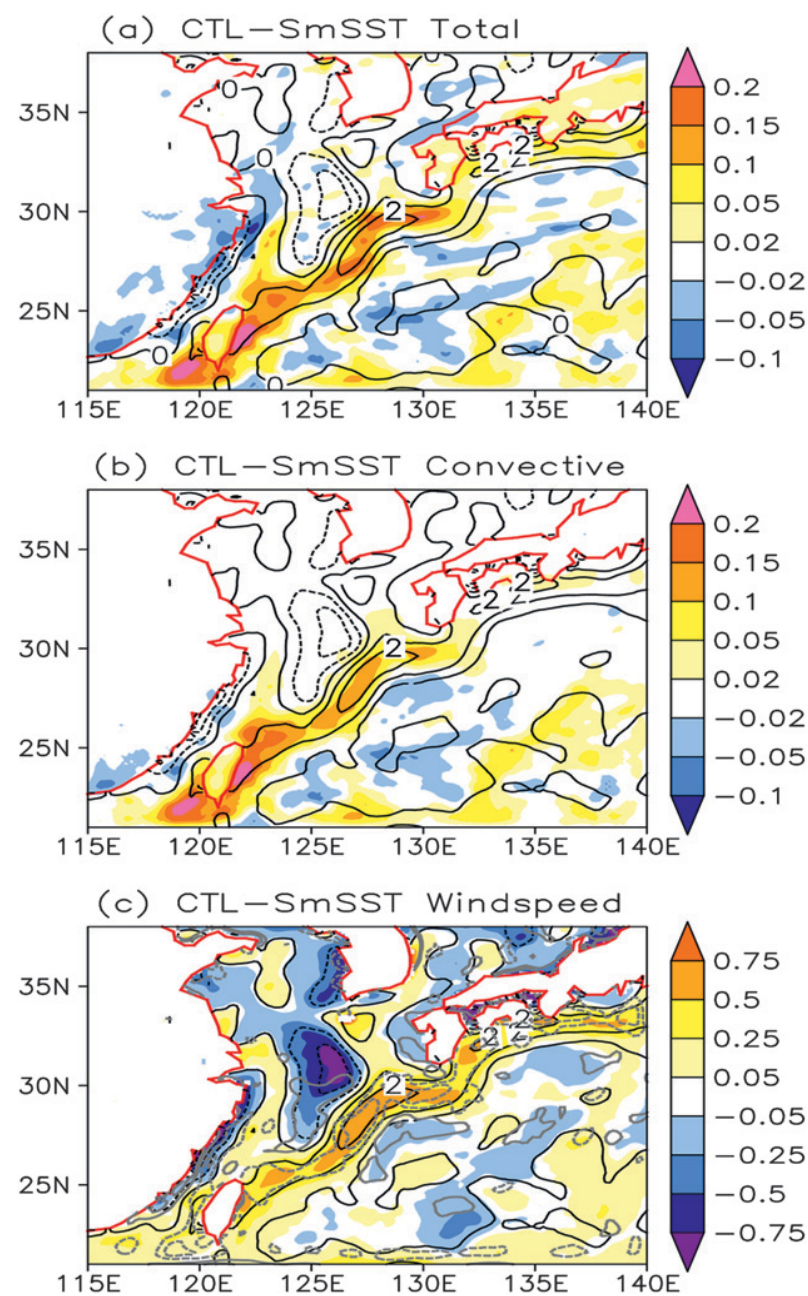

FIG. 8. Difference of (a) total and (b) convective precipitation rates (color in $\mathrm{mm} \mathrm{h}^{-1}$ ), (c) surface neutral equivalent wind speeds (color in $\mathrm{m} \mathrm{s}^{-1}$ ) and divergence (gray contours in $0.5 \times 10^{-5} \mathrm{~m} \mathrm{~s}^{-1}$ with 0 contour omitted) between CTL and SmSST runs, averaged for April-May 2006. The 2-month (April-May 2006) mean SST difference (black contours at $1.0^{\circ} \mathrm{C}$ intervals) between CTL and SmSST runs is also plotted.

\section{c. Surface winds, convergence, and vertical motion}

The QuikSCAT measures wind stress on the sea surface. The stress is not just related to background wind speed at some height above the surface but also to the static stability of the surface layer (Liu and Tang 1996). In the QuikSCAT product, the stress is related uniquely to neutral equivalent wind at $10 \mathrm{~m}$. For this reason the neutral equivalent wind speed at $10 \mathrm{~m}$ is used to compare the model and observed values of wind velocity near the surface. We derive the model neutral equivalent 10-m wind speed as follows:

$$
u(z)=\frac{u^{*}}{\kappa}\left(\ln \frac{10}{z_{0}}\right),
$$

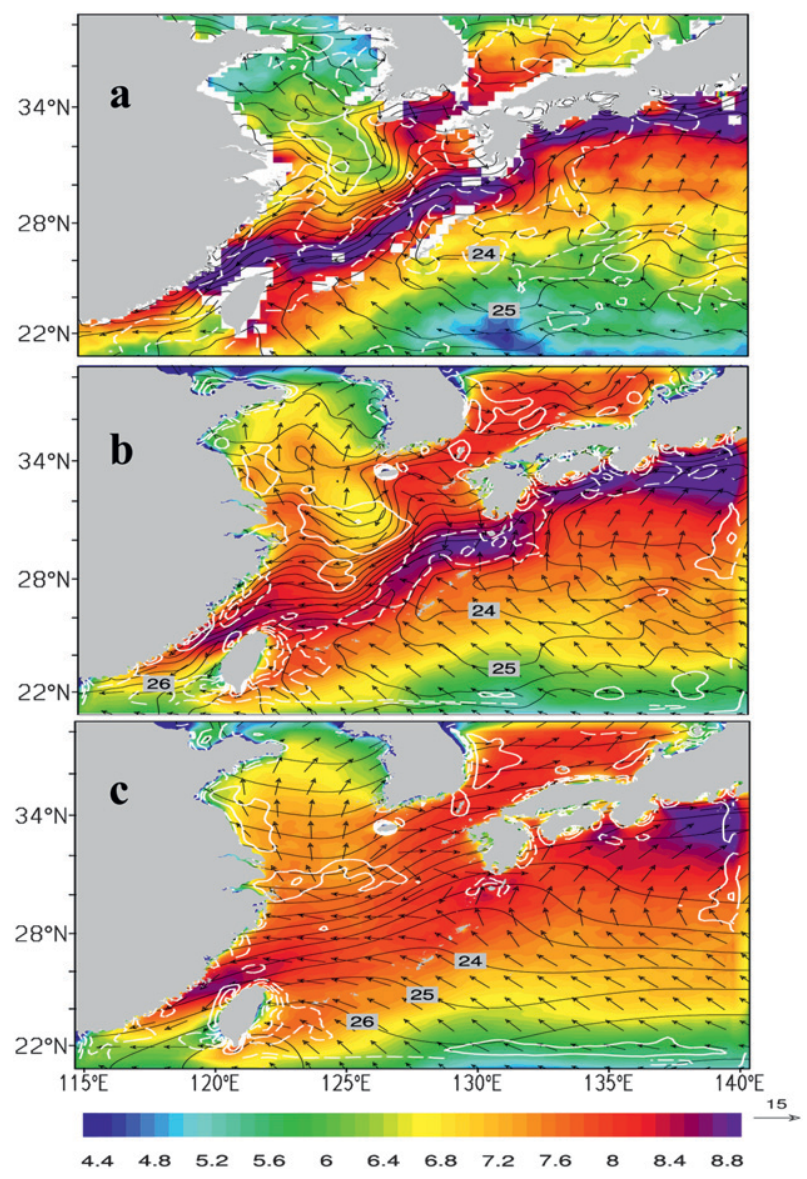

FIG. 9. The 2-month (April and May 2006) mean surface neutral equivalent wind vectors $\left(\mathrm{m} \mathrm{s}^{-1}\right)$, neutral equivalent wind velocities ( shade in $\mathrm{m} \mathrm{s}^{-1}$ ), and divergences (white contours at $0.5 \times 10^{-5} \mathrm{~s}^{-1}$ intervals with 0 contour omitted) for (a) QuikSCAT observations, (b) model CTL, and (c) SmSST runs. The 2-month (April-May 2006) mean SSTs (black contours at $1.0^{\circ} \mathrm{C}$ intervals) for (a) NCDC AVHRR observations, (b) CTL, and (c) SmSST runs are also plotted.

where $\kappa$ is von Kármán constant. The friction velocity $u^{*}$ and the roughness length $z_{0}$ are derived from the model data at the lowest model sigma level ( $\sigma=0.996$, at around $31 \mathrm{~m}$ ) and the known SST distributions, using the Fairall et al. (1996) surface layer algorithm.

Figure 9 presents the two-month (April-May 2006) mean 10-m surface neutral equivalent wind field and associated divergence from QuikSCAT observation, model CTL, and SmSST runs. The model (CTL run) simulates well the surface wind and divergence fields (Fig. 9b) in comparison with those from the QuikSCAT observations (Fig. 9a). In particular, the model well captures the enhanced (reduced) wind speed and convergence (divergence) fields over the warm (cold) tongue. However, the model produces higher (lower) surface wind speed by $0.4 \mathrm{~m} \mathrm{~s}^{-1}$ over the warm (cold) tongue compared to 

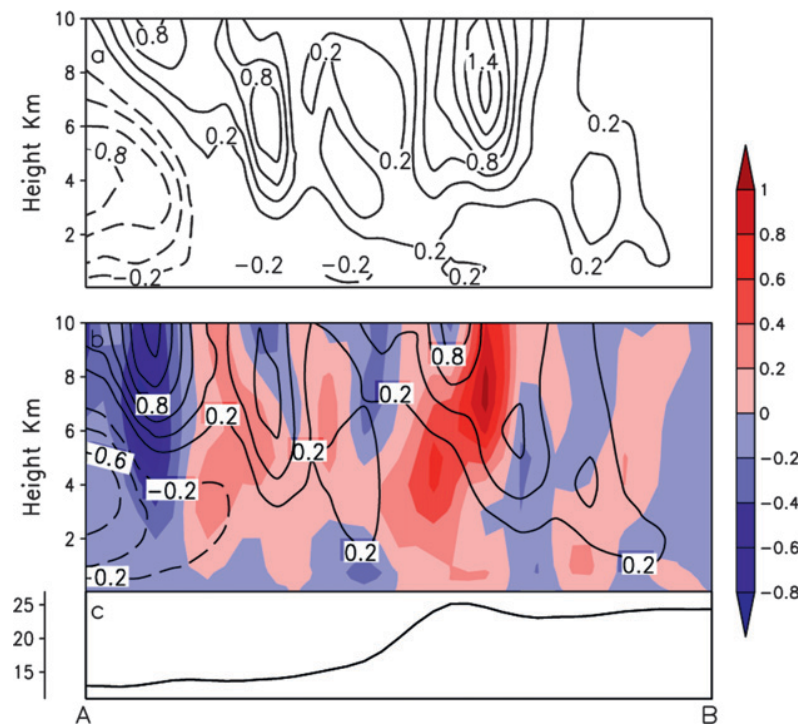

FIG. 10. Vertical cross sections of the 2-month mean (April and May 2006) vertical velocities (contours at intervals of $0.2 \times$ $10^{-2} \mathrm{~m} \mathrm{~s}^{-1}$ ) along line AB in Fig. 2a for model (a) CTL and (b) SmSST runs, and their differences (CTL minus SmSST; shaded in $10^{-2} \mathrm{~m} \mathrm{~s}^{-1}$ ). The corresponding (c) 2-month mean SST $\left({ }^{\circ} \mathrm{C}\right)$ in the CTL run along line $\mathrm{AB}$ is plotted.

the QuikSCAT observations. This difference is possibly due to the weak response of vertical turbulent mixing to SST-induced variability in the parameterization of boundary layer turbulence (Song et al. 2009). In addition, the strong underlying surface currents in this region could also contribute to the surface wind differences between WRF and QuikSCAT because QuikSCAT measures the actual wind stress on the moving sea surface rather than relative to a stationary sea surface (O'Neill et al. 2005), while the sea surface in the WRF model is set to be motionless. As pointed out in section 3a, the actual value of near-surface wind may differ from the surface neutral equivalent wind speed. Thus we compare the twomonth mean 10-m neutral equivalent wind speed with the unadjusted 10-m wind speed simulated by the WRF model (not shown). The neutral equivalent wind speed fields are similar to those of the unadjusted wind speed, with high (low) surface wind speed over the warm (cold) tongue and large wind speed changes across the Kuroshio SST front except that the neutral equivalent wind speed is larger than the unadjusted wind speed by $\sim 0.5 \mathrm{~m} \mathrm{~s}^{-1}$.

With the Kuroshio warm tongue removed in the SmSST run, the surface wind and convergence distributions are markedly changed (Fig. 9c). Without the warm and cold tongues, the surface winds become smooth in space, in contrast to the large variations in the CTL run. In particular, the aforementioned high wind speed and convergence fields along the Kuroshio warm tongue almost disappear. The effect of the Kuroshio warm tongue can be seen more clearly in the difference map between the CTL and SmSST runs (Fig. 8c). An increase in SST along the warm tongue is collocated with an increase in both surface wind speed and surface convergence, indicating that the Kuroshio acts to increase surface wind speed and thus enhance surface convergence. This enhanced surface convergence along the warm tongue is consistent with the increased precipitation shown in Fig. 8a.

Figure 10 shows vertical cross sections of the twomonth (April-May 2006) mean vertical velocity along the line AB for the CTL and SmSST runs. Consistent with the surface convergence fields in the CTL run (Fig. 9b), strong upward motion occurs in the middle and upper troposphere just above the Kuroshio warm tongue (Fig. 10a), with a maximum upward motion center at an altitude of $7 \mathrm{~km}$. With the Kuroshio warm tongue removed in the SmSST run, the aforementioned upward motion is markedly reduced and the associated maximum upward motion center also disappears (Fig. 10b). The effect of the Kuroshio warm tongue on vertical motion can be seen more clearly in the difference map between the CTL and SmSST runs (Fig. 10b), with marked positive anomalies in the middle and upper troposphere, indicative of deep atmospheric response along the Kuroshio.

\section{d. Cumulus convection analysis}

Analyses in the previous subsections suggest that it is cumulus convection not stratiform precipitation that is sensitive to the Kuroshio SST front and predominantly contributes to the narrow precipitation band formation. This subsection investigates the mechanisms by which the Kuroshio SST front anchors cumulus precipitation. Here, we consider an eastward-moving extratropical cyclone case for the period of 4-8 May 2006. This cyclone first develops over mainland China, then moves eastward and produces rainfall over the East China Sea.

Figure 11 shows the evolution of convective and stratiform precipitation in the distance-time sections along line $A B$ in Fig. 2a, together with surface winds, upward sensible and latent heat fluxes, SST and surface air temperature (SAT) difference, and convective available potential energy (CAPE). ${ }^{1} \mathrm{CAPE}$ is calculated using 3-hourly output by following a parcel that is adiabatically raised from $950 \mathrm{hPa}$ to the level of neutral buoyancy. As shown in Fig. 11, before the extratropical cyclone reaches the Kuroshio Front, southeasterly winds prevail over the East China Sea. Over the colder side of the SST front, these surface southeasterlies cause warm advection and stabilize

\footnotetext{
${ }^{1}$ Negative latent heat fluxes are not allowed in the model surface layer scheme.
} 


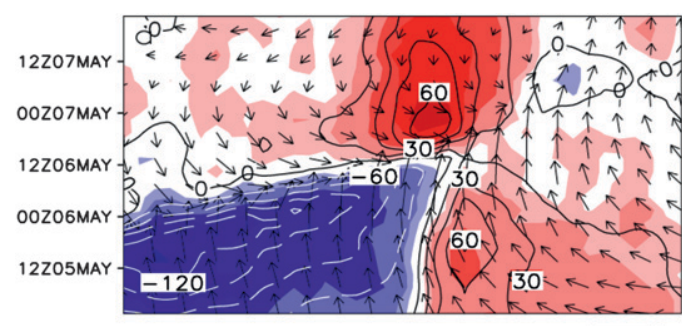

$\overrightarrow{20}$
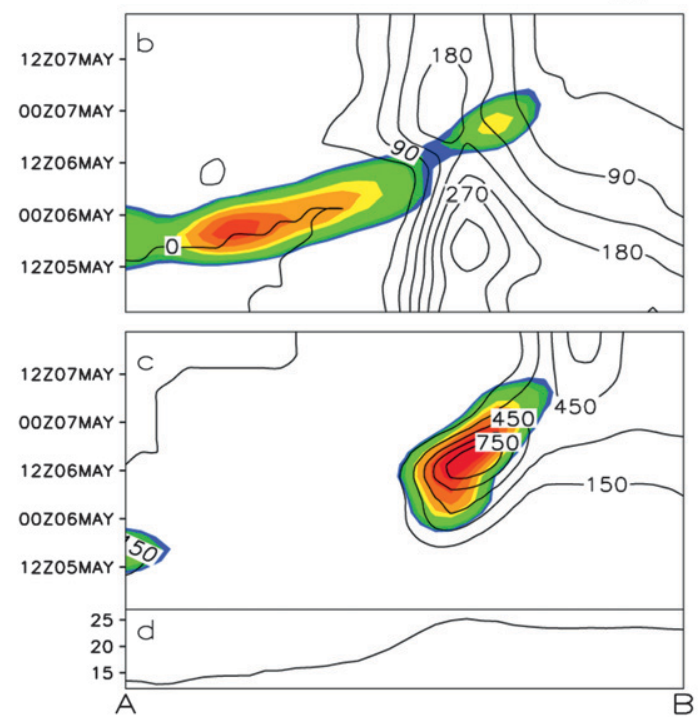

FIG. 11. Temporal cross sections along line AB in Fig. 2a of (a) surface wind vectors $\left(\mathrm{m} \mathrm{s}^{-1}\right)$, SST-SAT ( shade in ${ }^{\circ} \mathrm{C}$ ), sensible heat fluxes (positive upward; contours in $\mathrm{W} \mathrm{m}^{-2}$ ), (b) latent heat fluxes (positive upward; contours in $\mathrm{W} \mathrm{m}^{-2}$ ), stratiform precipitation rates (shade in $\mathrm{mm} \mathrm{h}^{-1}$ ), and (c) convective precipitation rates (shade in $\mathrm{mm} \mathrm{h}^{-1}$ ) and CAPE (contours at intervals of $150 \mathrm{~J} \mathrm{~kg}^{-1}$ ) for the period of 5-7 May 2006 in the model CTL run. The 3-day (5-7 May) mean SST $\left({ }^{\circ} \mathrm{C}\right)$ along line $\mathrm{AB}$ is plotted in (d).

the surface layer, with negative SST-SAT and downward (i.e., negative) sensible heat flux (Fig. 11a). At this time stratiform precipitation dominates over these regions (Fig. 11b). However, along the narrow Kuroshio warm current, relatively cold air advected by the southeasterly winds from its southeastern side turns SST-SAT positive to yield upward (i.e., positive) sensible and latent heat fluxes, destabilizing the lower troposphere. Upward surface latent and sensible heat fluxes reach their local maxima of over 60 and $315 \mathrm{~W} \mathrm{~m}^{-2}$, respectively, just south of the SST front. As the extratropical cyclone and accompanied northwesterlies approach the Kuroshio Front, convective precipitation is initiated and lasts for more than two days. This convective activity is highly collocated with a high CAPE center.

The evolutions of the SST-SAT, upward sensible heat flux, and stratiform precipitation over the colder flank of
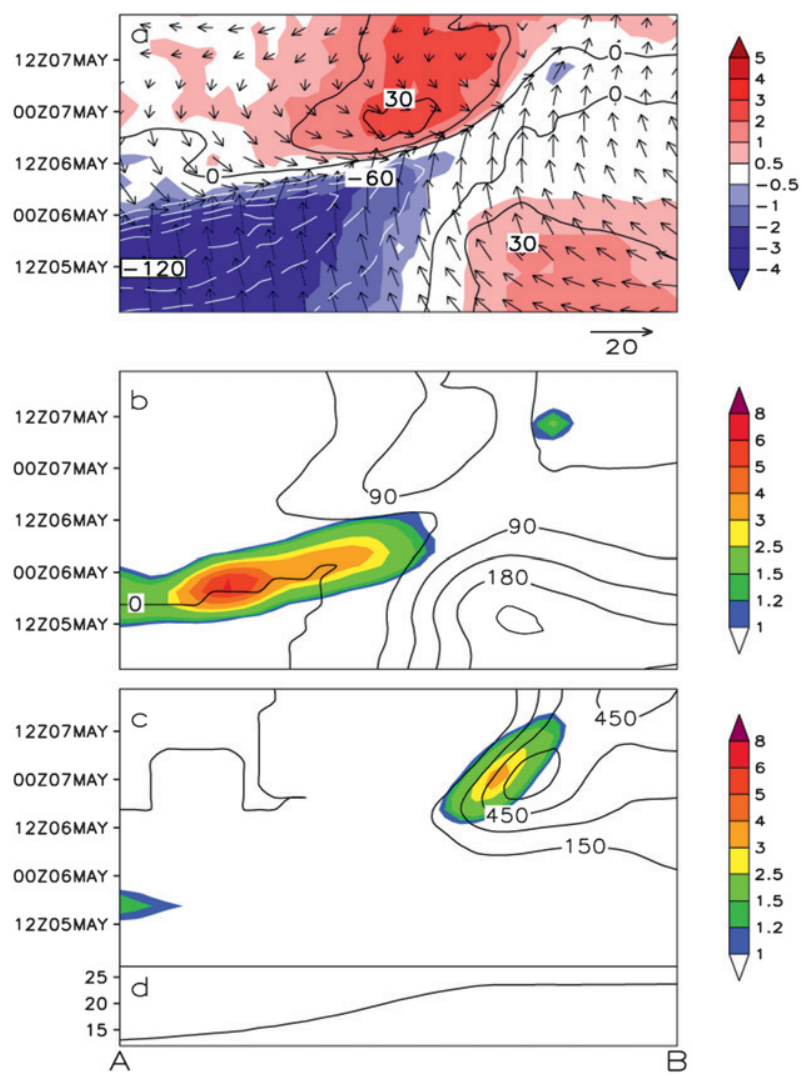

FIG. 12. As in Fig. 10, but for the model SmSST run.

Kuroshio Front in the SmSST run are almost the same as in the CTL run, however, they change markedly over the warmer flank (Fig. 12). Both the upward sensible and latent heat fluxes decrease in magnitude and spread broadly over the warmer side. Convective precipitation still appears in the SmSST run but substantially decreases in its intensity compared to that in the CTL run and only lasts one and half days, half a day less than in the CTL run. Moreover, the area of convective precipitation shifts southeastward, not confined spatially over the narrow Kuroshio as in the CTL run. A CAPE center still exists in the SmSST run, but substantially decreases in its magnitude, consistent with weak convective precipitation in the SmSST run.

CAPE is frequently regarded as an indicator of the potential intensity of deep convection. Variations in CAPE can be accounted for mostly by changes in the temperature and humidity in the planetary boundary layer (Donner and Phillips 2003). Figure 13 presents the 950-hPa temperature and specific humidity differences between the CTL and SmSST runs at 0012 UTC 6 May, when CAPE reaches its maximum in the CTL run. It is found that positive temperature and humidity anomalies are collocated with the underlying positive SST anomalies, 

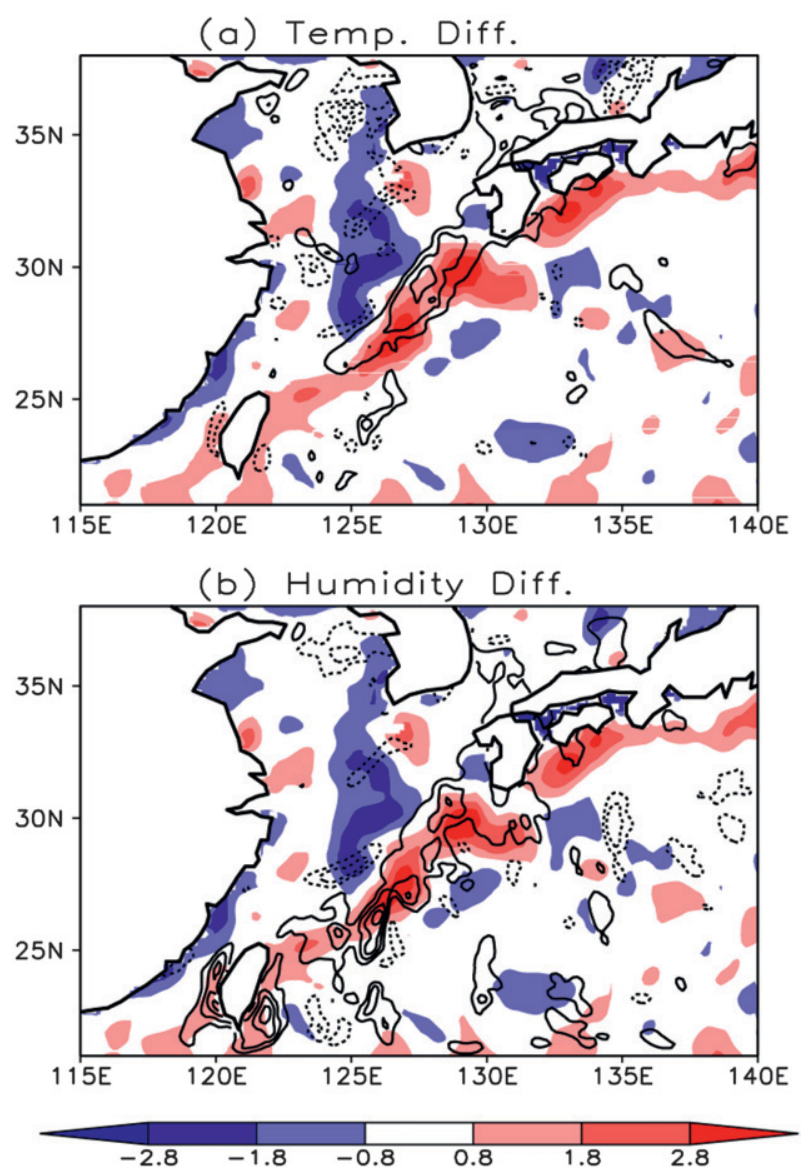

FIG. 13. Difference in (a) $950-\mathrm{hPa}$ temperature (contours at intervals of $0.4^{\circ} \mathrm{C}$ with 0 contour omitted) and (b) specific humidity (contours at intervals of $0.4 \mathrm{~g} \mathrm{~kg}^{-1}$ with 0 contour omitted) at 1200 UTC 6 May between the CTL and SmSST runs. The corresponding SST $\left({ }^{\circ} \mathrm{C}\right)$ difference between CTL and SmSST runs is also plotted in shade.

that is, the Kuroshio warm tongue in the East China Sea, indicating that the increased CAPE in the CTL run is mainly due to the increased temperature and humidity in the lower troposphere through the enhanced upward sensible and latent heat fluxes along the Kuroshio.

\section{Summary}

In the spring season, the Kuroshio warm current leaves a visible warm tongue and an associated sharp SST front over the East China Sea. Here, we examine the atmospheric response to this Kursohio front based on a suite of high-resolution satellite data and highresolution atmospheric model simulations. The atmospheric response to the Kuroshio Front appears to extend beyond the marine atmospheric boundary layer, with frequent occurrence of cumulus convection.
In spring, QuikSCAT wind speed shows a clear association with SST, with high (low) wind speed observed over the warm (cold) tongue. This in-phase relationship between SST and surface wind speed is indicative of SST influencing the atmosphere. Strong surface neutral wind convergence is found on the warmer flank of the Kuroshio Front, accompanied with a narrow precipitation band. The TRMM 2A25 product, which distinguishes convective and stratiform precipitation from the vertical structure of precipitation radar echo, indicates that cumulus convection appears over the Kuroshio warm tongue in the spring season, with enhanced convective precipitation, frequent occurrence of cumulus convection, and high precipitation (cloud) tops in altitude. These deep convection activities along the Kuroshio warm tongue are further supported by enhanced lightning flash rate by the LIS/OTD and atmospheric heating estimated by the Japanese reanalysis dataset, characterized by latent heating in the middle and upper troposphere due to deep convection.

The WRF model is used to investigate the atmospheric response to the Kuroshio SST front over the East China Sea, with a focus on mechanisms responsible for the formation of the narrow precipitation band on the warmer flank of the front. The CTL run, forced with high-resolution observed SSTs, reproduces major features of surface wind speed, precipitation, and surface wind convergence over the Kuroshio warm tongue similar to satellite observations. The SmSST run with smoothed SST, by contrast, failed to simulate several key observed features, particularly with the narrow precipitation band completely disappeared. It is the convective precipitation that is sensitive to the Kuroshio SST front. A case study for an eastward-moving extratropical cyclone indicates that convective precipitation increases in its intensity and duration in the CTL run compared to that in the SmSST run. This demonstrates that the SST front in the CTL run creates the narrow band of convective precipitation closely following the Kuroshio. Local enhancement of upward sensible and latent heat fluxes and convective instability in the lower troposphere along the warm Kuroshio are the key to anchoring the precipitation band.

Several other recent studies have reported similar modulation of surface wind convergence, cloud, and lightning by the Kuroshio Extension fronts (Joyce et al. 2009; Tokinaga et al. 2009). Tokinaga et al. (2009) showed deep penetration of upward motion in summer over the Kuroshio Extension, accompanied by frequent cloud-top occurrence around $400 \mathrm{hPa}$. The deep atmospheric response over the Gulf Stream is much more pronounced than that over the Kuroshio Extension because of sharper SST gradients with warmer SSTs from 
the Gulf Stream, larger cross-frontal changes in the surface heat flux, and surface wind convergence (Minobe et al. 2008; Minobe et al. 2010). Very recently, KuwanoYoshida et al. (2010) investigated the atmospheric response to the Gulf Stream using an atmospheric general circulation model. They showed that the Gulf Stream's effect on precipitation is mainly convective and that local enhancement of evaporation and surface convergence makes the Gulf Stream a favorable place for long-lasting convection in both winter and summer. In one of their experiments that removes the Gulf Stream SST front, the local enhancement of convective precipitation disappears along the Gulf Stream, consistent with our modeling results.

Acknowledgments. We wish to thank Jan Hafner at IPRC for archiving the TRMM and QuikSCAT data from Remote Sensing Systems. We are also grateful to three anonymous reviewers for their constructive comments, which helped to improve the paper. JRA-25 data are obtained from http://jra.kishou.go.jp/JRA-25. This work is supported by the Chinese Ministry of Science and Technology 973 Program (2010CB428505), NSFC (40975024), the Qianren and Changjiang Scholar Programs, the Japan Agency for Marine-Earth Science and Technology, and NASA.

\section{REFERENCES}

Awaka, J., T. Iguchi, H. Kumagai, and K. Okamoto, 1997: Rain type classification algorithm for TRMM Precipitation Radar. Proc. IGARSS'97, Singapore, Institute of Electrical and Electronics Engineers, 1633-1635.

,$--\ldots$, and K. Okamoto, 2007: Rain type classification algorithm. Measuring Precipitation from Space: EURAINSAT and the Future, V. Levizzani, P. Bauer, and F. Turk, Eds., Springer, 213-224.

Beljaars, A. C. M., 1994: The parameterization of surface fluxes in large-scale models under free convection. Quart. J. Roy. Meteor. Soc., 121, 255-270.

Chelton, D. B., and S.-P. Xie, 2010: Coupled ocean-atmosphere interaction at oceanic mesoscales. Oceanography, 23, $52-69$.

_- M. G. Schlax, M. H. Freilich, and R. F. Milliff, 2004: Satellite measurements reveal persistent small-scale features in ocean winds. Science, 303, 978-983.

Chen, F., and J. Dudhia, 2001: Coupling an advanced land surface/ hydrology model with the Penn State/NCAR MM5 modeling system. Part I: Model description and implementation. Mon. Wea. Rev., 129, 569-585.

Chen, S. H., and W. Y. Sun, 2002: A one-dimensional time dependent cloud model. J. Meteor. Soc. Japan, 80, 99-118.

Christian, H. J., and Coauthors, 2003: Global frequency and distribution of lightning as observed from space by the Optical Transient Detector. J. Geophys. Res., 108, 4005, doi:10.1029/ 2002JD002347.

Donner, L. J., and V. T. Phillips, 2003: Boundary layer control on convective available potential energy: Implications for cumulus parameterization. J. Geophys. Res., 108, 4701, doi:10.1029/ 2003JD003773.

Dudhia, J., 1989: Numerical study of convection observed during the winter monsoon experiment using a mesoscale two-dimensional model. J. Atmos. Sci., 46, 3077-3107.

Dyer, A. J., and B. B. Hicks, 1970: Flux-gradient relationships in the constant flux layer. Quart. J. Roy. Meteor. Soc., 96, $715-721$.

Fairall, C. W., E. F. Bradley, D. P. Rogers, J. B. Edson, and G. S. Young, 1996: Bulk parameterization of air-sea fluxes for Tropical Ocean-Global Atmosphere Coupled Ocean Atmosphere Research Experiment. J. Geophys. Res., 110, 37473764.

Graham, N. E., and T. P. Barnett, 1987: Sea surface temperature, surface wind divergence, and convection over tropical oceans. Science, 238, 657-659.

Hashizume, H., S.-P. Xie, W. T. Liu, and K. Takeuchi, 2001: Local and remote atmospheric response to tropical instability waves: A global view from space. J. Geophys. Res., 106, $10173-$ 10185 .

- _ - M. Fujiwara, M. Shiotani, T. Watanabe, Y. Tanimoto, W. T. Liu, and K. Takeuchi, 2002: Direct observations of atmospheric boundary layer response to SST variations associated with tropical instability waves over the eastern equatorial Pacific. J. Climate, 15, 3379-3393.

Hirose, M., and K. Nakamura, 2002: Spatial and seasonal variation of rain profiles over Asia observed by spaceborne precipitation radar. J. Climate, 15, 3443-3458.

Hong, S. Y., Y. Noh, and J. Dudhia, 2006: A new vertical diffusion package with an explicit treatment of entrainment processes. Mon. Wea. Rev., 134, 2318-2341.

Houze, R. A., Jr., D. C. Wilton, and B. F. Smull, 2007: Monsoon convection in the Himalayan region as seen by the TRMM Precipitation Radar. Quart. J. Roy. Meteor. Soc., 133, 13891411.

Iguchi, T., T. Kozu, R. Meneghini, J. Awaka, and K. Okamoto, 2000: Rain-profiling algorithm for the TRMM Precipitation Radar. J. Appl. Meteor., 39, 2038-2052.

Joyce, T. M., Y. O. Kwon, and L. Yu, 2009: On the relationship between synoptic wintertime atmospheric variability and path shifts in the Gulf Stream and the Kuroshio Extension. J. Climate, 22, 3177-3192.

Kain, J. S., 2004: The Kain-Fritsch convective parameterization: An update. J. Appl. Meteor., 43, 170-181.

, and J. M. Fritsch, 1990: A one-dimensional entraining/ detraining plume model and its application in convection parameterization. J. Atmos. Sci., 47, 2784-2802.

, and - 1993: Convective parameterization for mesoscale models: The Kain-Fritsch scheme. The Representation of Cumulus Convection in Numerical Models, K. A. Emanuel and D. J. Raymond, Eds., Amer. Meteor. Soc., 246 pp.

Klein, S. A., and D. L. Hartmann, 1993: The seasonal cyclone of low stratiform clouds. J. Climate, 6, 1587-1606.

Kuwano-Yoshida, A., S. Minobe, and S.-P. Xie, 2010: Precipitation response to the Gulf Stream in an atmospheric GCM. J. Climate, 23, 3676-3698.

Lindzen, R. S., and R. S. Nigam, 1987: On the role of sea surface temperature gradients in forcing low level winds and convergence in the tropics. J. Atmos. Sci., 44, 2418-2436.

Liu, W. T., and W. Tang, 1996: Equivalent neutral wind. Jet Propulsion Laboratory Publication 96-17, 6 pp.

, X. Xie, P. O. Polito, S.-P. Xie, and H. Hashizume, 2000: Atmospheric manifestation of tropical instability waves 
observed by QuikSCAT and Tropical Rainfall Measuring Mission. Geophys. Res. Lett., 27, 2545-2548.

Minobe, S., A. Kuwano-Yoshida, N. Komori, S.-P. Xie, and R. J. Small, 2008: Influence of the Gulf Stream on the troposphere. Nature, 452, 206-209.

—-, M. Miyashita, A. Kuwano-Yoshida, H. Tokinaga, and S.-P. Xie, 2010: Atmospheric response to the Gulf Stream: Seasonal variations. J. Climate, 23, 3699-3719.

Mlawer, E. J., S. J. Taubman, P. D. Brown, M. J. Iacono, and S. A. Clough, 1997: Radiative transfer for inhomogeneous atmosphere: RRTM, a validated correlated-k model for the longwave. J. Geophys. Res., 102 (D14), 16 663-16 682.

Monahan, E. C., 2008: Mapping high sea winds from space: A global climatology. Bull. Amer. Meteor. Soc., 89, 1379.

NASA Goddard Space Flight Center, 2011: File specifications for TRMM products-level 2 and level 3 (release 6.10). Vol. 4, Tropical Rainfall Measuring Mission (TRMM) Science Data and Information System (TSDIS), NASA Goddard Space Flight Center TSDIS documents. [Available online at http:// pps.gsfc.nasa.gov/tsdis_redesign/SelectedDocs.html.]

Nonaka, M., and S.-P. Xie, 2003: Covariations of sea surface temperature and wind over the Kuroshio and its extension: Evidence for ocean-to-atmospheric feedback. J. Climate, 16, 1404-1413.

Norris, J. R., 1998a: Low cloud type over the ocean from surface observations. Part I: Relationship to surface meteorology and the vertical distribution of temperature and moisture. J. Climate, 11, 369-382.

1998b: Low cloud type over the ocean from surface observations. Part II: Geographical and seasonal variations. J. Climate, 11, 383-403.

- and S. F. Iacobellis, 2005: North Pacific cloud feedbacks inferred from synoptic-scale dynamic and thermodynamic relationships. J. Climate, 18, 4862-4878.

_, Y. Zhang, and J. M. Wallace, 1998: Role of low clouds in summertime atmosphere-ocean interactions over the North Pacific. J. Climate, 11, 2482-2490.

O'Neill, L. W., D. B. Chelton, and S. K. Esbensen, 2003: Observations of SST-induced perturbations of the wind stress field over the Southern Ocean on seasonal timescales. J. Climate, 16, 2340-2354.

$\longrightarrow,-\longrightarrow$, , and F. J. Wentz, 2005: High-resolution satellite measurements of the atmospheric boundary layer response to SST variations along the Agulhas Return current. J. Climate, 18, 2706-2723.

Onogi, K., and Coauthors, 2007: The JRA-25 Reanalysis. J. Meteor. Soc. Japan, 85, 369-432.

Paulson, C. A., 1970: The mathematical representation of wind speed and temperature profiles in the unstable atmospheric surface layer. J. Appl. Meteor., 9, 857-861.

Reynolds, R. W., and D. B. Chelton, 2010: Comparisons of daily sea surface temperature analyses for 2007-08. J. Climate, 23, 3545-3562.

, T. M. Smith, C. Liu, D. B. Chelton, K. S. Casey, and M. G. Schlax, 2007: Daily high-resolution blended analyses for sea surface temperature. J. Climate, 20, 5473-5496.
Romatschke, U., S. Medina, and R. A. Houze Jr., 2010: Regional, seasonal, and diurnal variations of extreme convection in the South Asian region. J. Climate, 23, 419-439.

Sampe, T., and S.-P. Xie, 2007: Mapping high sea winds from space: A global climatology. Bull. Amer. Meteor. Soc., 88, 1965-1978.

Skamarock, W. C., and Coauthors, 2008: A description of the advanced research WRF version 3. NCAR Tech. Note NCAR/ TN-475+STR, 88 pp.

Small, R. J., S.-P. Xie, and Y. Wang, 2003: Numerical simulation of atmospheric response to Pacific tropical instability waves. J. Climate, 16, 3722-3737.

— , and Coauthors, 2008: Air-sea interaction over ocean fronts and eddies. Dyn. Atmos. Oceans, 45, 274-319.

Song, Q., D. B. Chelton, S. K. Esbensen, N. Thum, and L. O'Neill, 2009: Coupling between sea surface temperature and low-level winds in mesoscale numerical models. J. Climate, 22, 146-163.

Sud, Y. C., G. K. Walker, and K.-M. Lau, 1999: Mechanisms regulating sea surface temperatures and deep convection in the tropics. Geophys. Res. Lett., 26, 1019-1022.

Tokinaga, H., Y. Tanimoto, and S.-P. Xie, 2005: SST-induced surface wind variations over the Brazil-Malvinas confluence: Satellite and in situ observations. J. Climate, 18, 3470-3482.

_ and Coauthors, 2006: Atmospheric sounding over the winter Kuroshio Extension: Effect of surface stability on atmospheric boundary layer structure. Geophys. Res. Lett., 33, L04703, doi:10.1029/2005GL025102.

_- Y. Tanimoto, S.-P. Xie, T. Sampe, H. Tomita, and H. Ichikawa, 2009: Ocean frontal effects on the vertical development of clouds over the western North Pacific: In situ and satellite observations. J. Climate, 22, 4241-4260.

Wallace, J. M., T. P. Mitchell, and C. Deser, 1989: The influence of sea surface temperature on sea surface wind in the eastern equatorial Pacific: Seasonal and interannual variability. J. Climate, 2, 1492-1499.

Webb, E. K., 1970: Profile relationships: The log-linear range, and extension to strong stability. Quart. J. Roy. Meteor. Soc., 96, 67-90.

Xie, S.-P., 2004: Satellite observations of cool ocean-atmosphere interaction. Bull. Amer. Meteor. Soc., 85, 195-208.

_- M. Ishiwatari, H. Hashizume, and K. Takeuchi, 1998: Coupled ocean-atmospheric waves on the equatorial front. Geophys. Res. Lett., 25, 3863-3866.

_ J. Hafner, Y. Tanimoto, W. T. Liu, H. Tokinaga, and H. Xu, 2002: Bathymetric effect on the winter sea surface temperature and climate of the Yellow and East China Seas. Geophys. Res. Lett., 29, 2228, doi:10.1029/2002GL015884.

— H. Xu, N. H. Saji, and Y. Wang, 2006: Role of narrow mountains in large-scale organization of Asian monsoon convection. J. Climate, 19, 3420-3429.

$\mathrm{Xu}, \mathrm{H}$., H. Tokinaga, and S.-P. Xie, 2010: Atmospheric effects of the Kuroshio large meander during 2004-05. J. Climate, 23, 4704-4715.

Yang, S., and E. A. Smith, 2008: Convective-stratiform precipitation variability at seasonal scale from $8 \mathrm{yr}$ of TRMM observations: Implications for multiple modes of diurnal variability. J. Climate, 21, 4087-4114. 